\title{
Subsidized Marketplace Purchases Reduced Racial Disparities in Private Coverage Under the Affordable Care Act
}

\author{
Lonnie R. Snowden ${ }^{1} \cdot$ Neal Wallace $^{2} \cdot$ Genevieve Graaf $^{3}$ (D)
}

Received: 2 September 2021 / Revised: 11 November 2021 / Accepted: 3 December 2021 / Published online: 15 January 2022

c W. Montague Cobb-NMA Health Institute 2021

\begin{abstract}
The Affordable Care Act's Marketplaces, by allowing subsidized purchase of insurance coverage by persons with incomes from the poverty line to middle income, and through active outreach and enrollment assistance efforts, are well situated to reduce large African American-white private coverage disparities. Using data from the National Health Interview Survey for multiyear periods before and after Affordable Care Act implementation, from 2011-2013 to 2015-2018, this study assessed how much disparity reduction occurred when Marketplaces were implemented. Analysis compared private coverage takeup by African Americans and whites for persons with incomes between 100 and 400\% of the Federal Poverty Line (FPL), controlling for African American-white income differences and other covariates. African Americans' gains were significantly greater than whites' and disparities did close. However, both groups gained considerably less coverage than they might have, and some disparity remained. To make ongoing operations more effective and to guide future subsidy extensions and increases as enacted in the American Rescue Plan, more research is needed into the incentive value of subsidies and to discover which Marketplace outreach and enrollment assistance efforts were most effective. In advancing these aims, high priority should be given to identifying strategies that were particularly successful in reaching and engaging uninsured African Americans.
\end{abstract}

Keywords Affordable Care Act · Health disparities · Insurance coverage · Insurance subsidies · Health care Marketplace

The Affordable Care Act (ACA) expressly sought to advance health equity [1] by reducing longstanding African American-white health insurance coverage disparities [2, 3]. One avenue for disparity reduction was Medicaid expansion, conferring new eligibility on groups with significant African American overrepresentation, especially poor and nearpoor, non-elderly, and nondisabled adults [4]. Some African American-white coverage disparities appear to have declined after expansion by several percentage points [5-9].

Two ACA provisions facilitated gaining private insurance coverage in the drive to eliminate uninsurance. One, an

Genevieve Graaf

Genevieve.graaf@uta.edu

1 School of Public Health, University of California, Berkeley, 2121 Berkeley Way, Room 5302, Berkeley, CA 94720-7360, USA

2 OHSU-PSU School of Public Health, Portland State University, 1805 SW 4th Ave 523E, Portland, OR 97201, USA

3 School of Social Work, University of Texas, Arlington, 211 S. Cooper St., Arlington, TX 76017, USA employer mandate, required that employers with 50 or more full-time equivalent employees offer affordable "group coverage" [10], although most large employers already offered employer-sponsored coverage as a fringe benefit. Employer mandate gains were relatively small [10].

The ACA also greatly expanded the previously small market for "nongroup," individually purchased coverage by creating Health Insurance Marketplaces for which subsidies were available on a sliding scale. These "premium tax credits" were for persons with incomes between 100 and $400 \%$ Federal Poverty Line (FPL). "Cost sharing reductions" (CSRs) were also made available to defray out of pocket medical expenses for individuals with incomes up to $250 \%$ FPL [10]. Only Health Insurance Marketplaces provided access to premium tax credits and cost sharing reductions. Among subsidy-eligible persons, 91\% used Marketplaces for coverage purchases [11].

African Americans' median family income is only about 59\% that of whites [12] and, among uninsured African Americans eligible to purchase Marketplace plans, $86 \%$ qualified for subsidies [13]. Subsidized Marketplace purchases' potential for closing coverage disparities was even greater than 
Medicaid expansions': 1.6 times more uninsured African Americans, ages 19 to 62 years, were eligible for premium tax credits than for expanded Medicaid [13]. Marketplaces acted to raise public awareness of coverage requirements and possibilities. They provided standardized information about coverage in a streamlined format, which can ease administrative burden and increase enrollment [14]. Marketplaces made navigators and other assisters available for selection and enrollment in ACA-compliant plans and they offered subsidies available only through Marketplaces [15].

Many African Americans are hesitant to take-up government-sponsored benefits because of their aversive experiences with health programs [16] and with bureaucratic social programs [17], and because of wider mistrust of government fairness [18]. Nor have benefit programs always successfully reached out: qualified African Americans were less likely than whites to receive Coronavirus Aid, Relief, and Economic Security (CARES) Act support [19]. To encourage minority participation in Marketplaces, federal mandates stressed non-discrimination and culturally aware implementation [20]. Some state Marketplaces stressed outreach to members of ethnic minority communities [21,22].

The ACA research literature emphasizes disparity reduction in public, not private, coverage, or in "uninsurance" [5]. Medicaid expansion facilitated obtaining Medicaid, and many studies of the ACA's impact on African Americanwhite disparity reduction targeted Medicaid. Most studies of Medicaid expansion focused on "uninsurance" reduction, neglecting specification of the type or source of insurance coverage [23]. Aggregate gains from any coverage source conflate public and private coverage, and results from anysource studies cannot be interpreted as reflecting private coverage disparity reduction. Given the greater health care accessibility associated with private over public health coverage [24], isolating policies that can reduce disparities in private coverage is essential as these policies may hold superior power to reduce health care access and utilization disparities.

Unlike Medicaid expansion studies of public or any-source coverage, studies of disparity reductions in Marketplaceobtained private coverage are rare. One report compared whites' private coverage gains with gains in an ethnically heterogeneous category of "nonwhites"[8]. The "nonwhite" categorization lumps African Americans with other ethnic minority groups. Another study does address changes in African American-white private coverage disparities [5]. However, the study reports uncontrolled findings for only the initial year of the ACA, and it fails to isolate subsidy-eligible beneficiaries purchasing on Marketplaces. Other investigators [25] reported private coverage gains at state population rather than individual levels. They did not directly address disparities but did show that, for persons receiving subsidies in states with state-operated exchanges, as states' African American populations grew, so did gains in private coverage. More African Americans qualified for subsidized purchase of private coverage than for expanded Medicaid [13] but there are no national reports from controlled, individuallevel studies of American-white disparity reductions in private coverage among subsidy-eligible populations.

The Affordable Care Act represents a significant policy shift, but it is built upon deeply embedded existing health care policy [26] and has become inextricably integrated into our health care system [27]. As such, incremental theories of policy-making suggest that future health policy is likely to build upon the scaffolding erected under the ACA [28]. This is exemplified by the recently enacted American Rescue Plan Act, which extended and increased the Marketplace subsidies. This development demonstrates that, by varying subsidies' parameters and Marketplace outreach and engagement, policymakers continue to pursue key objectives. The likelihood that future health policy will build upon ACA-implemented structures reinforces the importance of understanding the potential of key levers in the ACA to reduce disparities.

Our objective was to estimate African American-white disparity reduction in private coverage rates following ACA Marketplace implementation. Contrasting outcomes could be expected. As African Americans responded to the ACA's coverage mandate, experiencing greater health-related need [29] and with pre-existing condition exclusions eliminated, disparities might decline: African Americans, needing coverage more, might exhibit greater responsiveness to subsidies, to advertising which sometimes targeted African American communities, and to Marketplace assistance. Alternatively, failure to address African American populations' hesitancy to participate in government-mandated programs might perpetuate structural inequalities and again leave African Americans at a relative disadvantage.

\section{Methods}

\section{Overview}

We investigated African American-white disparity reduction in private coverage rates following ACA Marketplace implementation. We did this by focusing on persons with income levels eligible for premium tax credits and cost sharing reductions through Marketplace health coverage purchases (100 to $400 \%$ FPL) and who lacked employer-sponsored private coverage. We used the National Health Interview Survey for the years 2011-2013 and 2015-2018, employing a difference-in-difference design to compare African Americans and whites rates of private insurance coverage before and after implementation of subsidized Marketplace purchase possibilities. To control for African Americans' eligibility for more generous subsidies and for expanded Medicaid, we control for African American-white differences in income. To eliminate persons who gained coverage 
from the employer mandate, and because availability of employer-sponsored coverage denied them eligibility for subsidies [15], we exclude respondents who indicated their employer offered health insurance coverage.

\section{National Health Interview Survey}

The National Health Interview Survey (NHIS) is a nationally representative, cross-sectional household interview survey of the civilian noninstitutionalized population of the USA. The survey is conducted by the National Center for Health Statistics (NCHS) of the Centers for Disease Control and Prevention (CDC) and is used widely throughout the Department of Health and Human Services (DHHS) to monitor trends in illness and disability and to track progress toward achieving national health objectives. Because NHIS data is publicly available, this study was exempt from Institutional Review Board approval.

\section{Sample and Measures}

The sample consisted of African American and non-Hispanic white adult US citizens, aged 18 to 64, with incomes between 100 and $400 \%$ FPL who indicated that their employer did not offer sponsored insurance coverage. The sample excluded those who reported receiving Social Security Income or Disability Insurance (SSI or SSDI) which potentially qualifiesthem for Medicaid. These study sample selection criteria yielded 29,825 individual observations, of which 4,387 identified as African American and 25,438 identified as non-Hispanic white.

The outcome was a dichotomous measure of private insurance coverage. The independent measures of primary interest were dichotomous indicators of African American status and post-ACA time period, and an indicator for the interaction between the African American and post-ACA period. These measures provide the difference-in-difference framework identifying pre-ACA differences in African American-white private coverage, pre- to post-ACA change in white private coverage, and differences in pre- to post-ACA private coverage change for African Americans and whites, respectively. ACA health exchanges were fully certified and operational by January 1, 2014, as provided under federal law. The preACA period was 2011-2013 and the post-ACA period was 2015-2018; we eliminated 2014 as an implementation year.

Additional control variables included demographics: age, gender, marital status and number of children, and education level. We included a functional limitation indicator to control partially for health-related motivation for seeking coverage. We also included income level to control for racial differences in eligibility for varying levels of subsidy generosity. All control variables were coded as single or multiple dichotomous measures. Observations with missing values
(Don't Know, Refused, and/or Not Ascertained) represented less than $0.2 \%$ of the total sample and were assigned to the excluded groups.

\section{Analysis}

We assessed power using Hu and Hoover's methods [30] for non-randomized difference-in-difference studies using the African American sub-sample as the effective sample size for each arm. Considering 7 total measurement periods ( 3 pre- and 4 post-) and assuming moderate correlation between study groups over time $(\mathrm{rho}=0.5)$, we found greater than $90 \%$ power to detect a 0.1 effect size.

We estimated a linear probability model (LPM) difference-in-difference design (D-in-D) accounting for the complex survey design of the NHIS. Accordingly, the coefficient of interaction between African American status and postACA period identifies the difference in pre- to post-ACA change in private coverage for African American versus whites. All coefficients from the LPM, including the D-inD effect noted above, can be interpreted as percentage point differences in private insurance coverage level.

All estimation used STATA 15 and employed the SRVY command to set and incorporate the multi-level NHIS survey design in the analyses. Consistent with recommendations for pooling annual NHIS data across varying implementation structures, which occurred once within the study period (2016), we recoded the survey strata for years after 2015 (added 1000 to strata number). Post-regression estimation included use of the MARGINS command to estimate marginal probabilities of private insurance coverage by African American-white, pre- and post-ACA. The NLCOM command was used to estimate changes in relative disparities, that is, the pre-post-ACA differences in the ratio of African American-white private coverage rates.

Difference-in-difference designs rest on an assumption of parallel trends in pre-intervention (ACA) coverage rates. We tested this assumption using the pre-ACA (2011-2013) data by regressing, on the private coverage indicator, the African American status indicator, a linear time trend, and the interaction of the time trend with the African American status indicator, along with the remaining control variables. The interaction term was not statistically significant, indicating that the hypothesis of parallel trends was not rejected, a finding consistent with the parallel trend assumption.

\section{Results}

Table 1 provides descriptive statistics for the sample across all study years. The weighted African American and white observations represented approximately 37.6 million individuals annually: $13.9 \%$ were African American (5.2 million 
Table 1 Sample demographics across all study years (20112013, 2015-2018)

\begin{tabular}{|c|c|c|c|}
\hline Variable & Total sample & African American & Non-Hispanic white \\
\hline Observations & 29,825 & 4,387 & 25,438 \\
\hline (Unweighted) Observation \% & $100 \%$ & $14.7 \%$ & $85.3 \%$ \\
\hline Average annual weighted population & $37,674,834$ & $5,244,337$ & $32,430,497$ \\
\hline Weighted population \% & $100 \%$ & $13.9 \%$ & $86.1 \%$ \\
\hline \multicolumn{4}{|l|}{ Private insurance coverage } \\
\hline No & $50.4 \%$ & $63.1 \%$ & $48.3 \%$ \\
\hline Yes & $49.6 \%$ & $36.9 \%$ & $51.7 \%$ \\
\hline \multicolumn{4}{|l|}{ ACA timeframe } \\
\hline Pre-ACA (2011-2013) & $43.4 \%$ & $42.1 \%$ & $43.6 \%$ \\
\hline Post-ACA (2015-2018) & $56.6 \%$ & $57.9 \%$ & $56.4 \%$ \\
\hline \multicolumn{4}{|l|}{ Age group } \\
\hline Age 18-26 & $28.5 \%$ & $31.3 \%$ & $28.5 \%$ \\
\hline Age $27-35$ & $17.6 \%$ & $17.7 \%$ & $17.6 \%$ \\
\hline Age $36-49$ & $24.1 \%$ & $23.0 \%$ & $24.1 \%$ \\
\hline Age 50-64 & $29.9 \%$ & $28.0 \%$ & $29.9 \%$ \\
\hline \multicolumn{4}{|l|}{ Functional limitation } \\
\hline No & $67.6 \%$ & $70.4 \%$ & $67.1 \%$ \\
\hline Yes & $32.4 \%$ & $29.6 \%$ & $32.9 \%$ \\
\hline \multicolumn{4}{|l|}{ Gender } \\
\hline Male & $44.7 \%$ & $47.3 \%$ & $44.3 \%$ \\
\hline Female & $55.3 \%$ & $52.7 \%$ & $55.7 \%$ \\
\hline \multicolumn{4}{|l|}{ Marital status } \\
\hline Married & $46 \%$ & $29 \%$ & $49 \%$ \\
\hline Was married & $12 \%$ & $15 \%$ & $12 \%$ \\
\hline Not married & $42 \%$ & $56 \%$ & $39 \%$ \\
\hline \multicolumn{4}{|l|}{ Number of children } \\
\hline None & $56.2 \%$ & $57 \%$ & $56 \%$ \\
\hline One & $19.0 \%$ & $22 \%$ & $19 \%$ \\
\hline Two & $15.5 \%$ & $14 \%$ & $16 \%$ \\
\hline Three or more & $9.3 \%$ & $8.2 \%$ & $9.5 \%$ \\
\hline \multicolumn{4}{|l|}{ Employment status } \\
\hline Not employed & $34.4 \%$ & $35.3 \%$ & $34.2 \%$ \\
\hline Employed & $65.6 \%$ & $64.7 \%$ & $65.8 \%$ \\
\hline \multicolumn{4}{|l|}{ Educational attainment } \\
\hline Less than high school/unknown & $13.1 \%$ & $14.7 \%$ & $12.9 \%$ \\
\hline High school & $30.6 \%$ & $35.1 \%$ & $29.8 \%$ \\
\hline Some college & $25.2 \%$ & $26.8 \%$ & $25.0 \%$ \\
\hline Associates degree & $11.9 \%$ & $10.3 \%$ & $12.1 \%$ \\
\hline Bachelor's degree & $14.6 \%$ & $10.3 \%$ & $15.3 \%$ \\
\hline Graduate degree & $4.6 \%$ & $2.9 \%$ & $4.8 \%$ \\
\hline \multicolumn{4}{|l|}{ Income level } \\
\hline 100-200\%FPL & $36.8 \%$ & $47.1 \%$ & $35.1 \%$ \\
\hline 200-300\% FPL & $26.5 \%$ & $25.1 \%$ & $26.7 \%$ \\
\hline $300-400 \%$ FPL & $19.6 \%$ & $14.7 \%$ & $20.4 \%$ \\
\hline$>200 \mathrm{FPL}^{1}$ & $17.2 \%$ & $13.1 \%$ & $17.8 \%$ \\
\hline
\end{tabular}

${ }^{1}$ Income greater than $200 \%$ but upper limit unknown annually) and $86.1 \%$ white (32.4 million annually). Approximately half of the sample had private coverage (49.6\%), with African Americans' rate (36.9\%) much lower than whites' rate
(51.7\%). African Americans were more likely than whites to be near-poor ( $47.1 \%$ vs. $35.1 \%$ ) and less likely to have incomes between 300 and $400 \%$ FPL (14.7\% vs $20.4 \%$ ). As expected, 
Table 2 Regression results for pre- to post-ACA differences in private insurance coverage for African Americans and whites with incomes between 100 and 400\% FPL and without employer coverage offers

\begin{tabular}{|c|c|c|c|c|c|}
\hline Variable & $\beta$ & SE & $95 \% \mathrm{CI}$ & & $p<$ \\
\hline African American & -0.088 & 0.013 & -0.113 & -0.062 & 0.000 \\
\hline Post-ACA & 0.038 & 0.007 & 0.023 & 0.052 & 0.000 \\
\hline $\begin{array}{l}\text { Post-ACA } \times \text { African } \\
\text { American }\end{array}$ & 0.044 & 0.019 & 0.007 & 0.081 & 0.020 \\
\hline \multicolumn{6}{|l|}{ Age group } \\
\hline Age 18-26 & 0.185 & 0.011 & 0.162 & 0.208 & 0.000 \\
\hline Age $27-35$ & -0.058 & 0.010 & -0.077 & -0.039 & 0.000 \\
\hline Age $50-64$ & 0.095 & 0.010 & 0.076 & 0.114 & 0.000 \\
\hline \multicolumn{6}{|l|}{ Functional limitation } \\
\hline Yes & -0.042 & 0.008 & -0.057 & -0.026 & 0.000 \\
\hline \multicolumn{6}{|l|}{ Gender } \\
\hline Female & 0.052 & 0.007 & 0.038 & 0.066 & 0.000 \\
\hline \multicolumn{6}{|l|}{ Marital status } \\
\hline Married & 0.195 & 0.009 & 0.177 & 0.212 & 0.000 \\
\hline Was married & -0.019 & 0.011 & -0.040 & 0.003 & 0.093 \\
\hline \multicolumn{6}{|l|}{ Number of children } \\
\hline One child & -0.024 & 0.010 & -0.043 & -0.004 & 0.019 \\
\hline Two children & 0.027 & 0.011 & 0.005 & 0.049 & 0.017 \\
\hline $\begin{array}{l}\text { Three or more chil- } \\
\text { dren }\end{array}$ & 0.053 & 0.013 & 0.027 & 0.079 & 0.000 \\
\hline \multicolumn{6}{|l|}{ Employment status } \\
\hline Employed & -0.029 & 0.008 & -0.045 & -0.015 & 0.000 \\
\hline \multicolumn{6}{|l|}{ Educational attainment } \\
\hline High school & 0.104 & 0.011 & 0.082 & 0.127 & 0.000 \\
\hline Some college & 0.188 & 0.012 & 0.165 & 0.211 & 0.000 \\
\hline Associates degree & 0.157 & 0.014 & 0.130 & 0.184 & 0.000 \\
\hline Bachelor's degree & 0.287 & 0.013 & 0.262 & 0.313 & 0.000 \\
\hline Graduate degree & 0.315 & 0.016 & 0.283 & 0.347 & 0.000 \\
\hline \multicolumn{6}{|l|}{ Income level } \\
\hline 200-300\% FPL & 0.174 & 0.009 & 0.157 & 0.191 & 0.000 \\
\hline $300-400 \%$ FPL & 0.302 & 0.010 & 0.283 & 0.321 & 0.000 \\
\hline$>200 \mathrm{FPL}^{1}$ & 0.291 & 0.011 & 0.269 & 0.314 & 0.000 \\
\hline Intercept & 0.015 & 0.014 & -0.014 & 0.043 & 0.307 \\
\hline
\end{tabular}

Excluded group is white, age 36-49, no functional limitations, male, not married, no children, not employed, less than high school or unknown education level, and income 100-200\% FPL

${ }^{1}$ Income greater than $200 \%$ but upper limit unknown

income disparities disproportionately entitled African Americans to more generous subsidies.

Table 2 presents regression results estimating differences in African American and white private coverage rates from preto post-ACA. The first three variables presented in Table 2African American, Post-ACA, and Post-ACA $\times$ African American-represent the estimates of private insurance disparity as detailed below. Table 3 presents marginal probabilities derived from the regression results of private insurance coverage for
African Americans and whites before and after the ACA and the change in relative disparity pre-to-post.

African Americans with incomes between 100 and 400\% FPL were $8.8 \%$ less likely than whites to have private coverage during the pre-ACA years (Table 2, African American $\beta=-0.088, \mathrm{SE}=0.013$ ) corresponding with pre-ACA estimates for African American of $39.5 \%$ versus $48.4 \%$ for white (Table 3). ACA implementation was associated with a $3.8 \%$ increase in private coverage for whites (post-ACA: $\beta=0.038$, $\mathrm{SE}=0.007$; Table 2) corresponding with marginal estimates of private coverage rising to $52.2 \%$ post-ACA from $48.4 \%$ preACA (Table 3). African Americans' gains were $4.4 \%$ greater than for whites (Table 2: Post-ACA $\times$ African American: $\beta=0.044, \mathrm{SE}=0.019)$ corresponding with marginal estimates of their private coverage rising to $47.8 \%$ post-ACA from $39.6 \%$ pre-ACA (Table 3). In terms of relative disparities, African Americans attained $81.8 \%$ of white private coverage rates preACA rising to $91.6 \%$ post-ACA for a $9.8 \%$ gain $(\beta=0.098$, $\mathrm{SE}=0.37$; Table 3).

\section{Discussion}

Among persons qualifying for Marketplace-offered subsidies, African Americans took-up private coverage more than whites and the African American-white disparity closed significantly. The private coverage disparity was not eliminated but substantial progress was made in reducing it to a level approaching African American-white equity. This is an important accomplishment with lessons for future disparity reduction efforts which are discussed below.

Viewed from a wider perspective, however, the results reveal large proportions of subsidy-eligible African Americans and whites who did not avail themselves of the new opportunity to obtain private coverage. In this respect, Marketplaces join other coverage opportunities, including Medicaid expansion, where take-up rates are far from the maximum [31]. One take-up deterrent was declining subsidies [10]. Thus, take-up rates declined with increasing income and declining subsidies, indicating that the increasing price of coverage may have proved formidable. The American Rescue Plan Act increases existing subsidies and extends them to higher income levels. These policy changes should be made permanent if they are equally effective in reducing disparities.

States' enthusiasm for implementing Marketplaces, and states' Marketplace performance, varied widely. Marketplace enrollment varied from about $20 \%$ of eligible persons to more than $70 \%$ [32], as some states merely acquiesced in adopting the federal Marketplace whereas others responded energetically by establishing state-sponsored Marketplaces. Some proactive states secured supplemental funding for their Marketplaces and employed innovative approaches for consumer engagement [21]. Vigorous implementation also included aggressive advertising, which was associated 
Table 3 Marginal estimates of African American and white private coverage pre- and postACA, relative disparities and relative disparity change

\begin{tabular}{|c|c|c|c|c|c|c|c|c|c|}
\hline \multirow[b]{2}{*}{ African American } & \multirow{2}{*}{$\frac{\text { Pre-ACA }}{39.5 \%}$} & \multicolumn{2}{|c|}{$95 \%$ CI } & \multirow{2}{*}{$\frac{p<}{0.00}$} & \multirow{2}{*}{$\frac{\text { Post-ACA }}{47.6 \%}$} & \multicolumn{2}{|c|}{$95 \% \mathrm{CI}$} & \multirow{2}{*}{$\frac{p<}{0.00}$} & \multirow{2}{*}{$\begin{array}{l}\text { Difference } \\
-\end{array}$} \\
\hline & & 0.37 & 0.42 & & & 0.45 & 0.50 & & \\
\hline White & $48.4 \%$ & 0.47 & 0.49 & 0.00 & $52.1 \%$ & 0.51 & 0.53 & 0.00 & - \\
\hline Relative disparity & $81.7 \%$ & 0.77 & 0.87 & 0.00 & $91.3 \%$ & 0.86 & 0.97 & 0.00 & $9.7 \%$ \\
\hline
\end{tabular}

with greater Marketplace shopping and enrollment in a Marketplace plan [33]. Overall, Marketplace functions have enjoyed varying levels of support from states depending on the state's political climate and hesitancy about the ACA [34]. More research is needed to understand Marketplace policies and operations to guide federal regulation seeking to steer Marketplaces to adopt best practices.

African Americans' favorable response may have occurred for several reasons. Subsidies may have been more valuable to African Americans than to whites in a manner that income controls failed to capture. Family size affects the value of income and the Federal Poverty Line measure used in the study adjusts for family size, as do other direct measures of family variables included in the study. Yet unmeasured factors, such as African Americans' greater employment and housing insecurity beyond what might be expected from low-income alone and greater vulnerability to crises [4] - and African Americans' very limited access to non-income-based resources and family wealth [35] — may have made subsidized purchase especially appealing to African Americans, contributing to greater African American uptake. Also, for disproportionately many African Americans with untreated illness [29], the opportunity to seek previously unaffordable but needed medical care may have increased the subsidy's value. More research is needed on the subsidy's incentive value, and the possibility of incomeby-subsidy interaction, in promoting African Americans acquiring coverage, and ultimately, in receiving health care.

Along with subsidies, Marketplace operations likely played a role. Marketplaces grappled with significant challenges to recruiting African Americans, confronting historic barriers to African American participation [36]. Some Marketplaces succeeded in reaching out to African Americans, and several practices may have helped to reduce disparities, as when minority involvement was sought in oversight and development of community-targeted advertising [22].

Health insurance's complexity represents another barrier to Marketplace participation [37] and may have affected African Americans especially. Nearly 50\% of uninsured potential Marketplace customers were unfamiliar with the concepts and terms composing insurance policies [38]. Standardized and streamlined presentation of information and culturally aware personal assistance [21] may have benefited African Americans who can face "stereotype threat" reactions [39], resulting in fear of race-based negative judgment from failure to understand complex policy provisions.
Navigators and other required assistors may have been especially beneficial for overcoming complexity barriers for African Americans. Navigators' required training sometimes focused on meeting the needs of underserved culturally diverse communities [21], which may have sometimes overcome mistrust and reached marginalized, mistrustful populations, including African Americans [40].

Success in reaching African Americans may have benefited from some states' enthusiastic embrace of the Marketplace's mission. Case studies [21,22] indicate that minorityresponsive Marketplaces were more likely to supplement Federal grant funding with private and foundation grants to assist in reaching out and enrolling ethnically diverse populations, and that they supplemented federal assister training programs with follow-up training on cultural competence and conducted post-training activities to address unforeseen barriers. Minority-aware Marketplaces consulted with stakeholders and advocates and created advisory groups and affiliated with faith-based institutions, childcare centers, and community health centers and other trusted venues for outreach and enrollment. These and other strategies should be documented and evaluated in rigorous research.

Several limitations apply to our findings which concern aggregate coverage over a 3 -year period. The study did not address attrition, nor did it address market or policy modifications during the post-ACA study period. Attrition was notable after initial enrollment [41], and our study does not consider how long covered persons were covered. Studies are needed of disparities in lapsed coverage, including lapsed and never renewed coverage.

Health insurance market conditions affect take-up, and they varied from place-to-place and over time. Declining participation became critical as insurers withdrew during earlier years of ACA implementation. Conceivably, when exposed to similar market conditions, all else being equal, African Americans and whites might respond in similar fashion, leaving disparities unaffected. However, hypotheses to the contrary should be entertained as this expectation remains untested. In general, research is needed on how Marketplace conditions effect disparities in take-up of Marketplace-offered private coverage.

A critical event, eliminating the "individual mandate"the penalty for lacking health insurance coverage, took effect in 2019. This is outside of the present study's post-ACA study period ending in 2018. However, for this reason, the present findings cannot be generalized with confidence to 
years after 2018. Research is needed to determine the impact of eliminating the mandate on disparities, as well as other post-2018 ACA developments.

Despite these limitations, we documented large multiyear increases in private health coverage for African Americans eligible for subsidized coverage and a reversal in disparities from pre-ACA levels. Better understanding the impact of subsidies and Marketplace policies and operations is a key area for future inquiry as we seek to advance equity in coverage, access, and health care provision.

Supplementary Information The online version contains supplementary material available at https://doi.org/10.1007/s40615-021-01204-3.

Author Contribution Dr. Snowden conceived of the study and drafted the manuscript. Dr. Wallace completed the analysis. Dr. Graaf provided substantive editing to the manuscript.

Data Availability Data is publicly available.

Code Availability Available upon request.

\section{Declarations}

Conflict of Interest The authors declare no competing interests.

\section{References}

1. Michener J. Race, politics, and the Affordable Care Act. J Health Polit Policy Law. 2020;45(4):547-66.

2. Guth M, Artiga, S \& Pham O Effects of the ACA Medicaid expansion on racial disparities in health and health care. 2020.

3. Cross-Call J. Medicaid expansion has helped narrow racial disparities in health coverage and access to care: JSTOR; 2020.

4. Snowden L, Graaf G. The, "undeserving poor", racial bias, and Medicaid coverage of African Americans. J Black Psychol. 2019;45(3):130-42.

5. Buchmueller TC, Levinson ZM, Levy HG, Wolfe BL. Effect of the Affordable Care Act on racial and ethnic disparities in health insurance coverage. Am J Public Health. 2016;106(8):1416-21.

6. Buchmueller TC, Levy HG. The ACA's impact on racial and ethnic disparities in health insurance coverage and access to care: an examination of how the insurance coverage expansions of the Affordable Care Act have affected disparities related to race and ethnicity. Health Aff. 2020;39(3):395-402.

7. Chen J, Vargas-Bustamante A, Mortensen K, Ortega AN. Racial and ethnic disparities in health care access and utilization under the Affordable Care Act. Medical care. 2016;54(2):140.

8. Courtemanche CJ, Fazlul I, Marton J, Ukert BD, Yelowitz A, Zapata D. The impact of the ACA on insurance coverage disparities after four years. National Bureau of Economic Research; 2019.

9. Yue D, Rasmussen PW, Ponce NA. Racial/ethnic differential effects of Medicaid expansion on health care access. Health Serv Res. 2018;53(5):3640-56.

10. French MT, Homer J, Gumus G, Hickling L. Key provisions of the Patient Protection and Affordable Care Act (ACA): a systematic review and presentation of early research findings. Health Serv Res. 2016;51(5):1735-71.
11. Fiedler M. Enrollment in nongroup health insurance by income group. 2021.

12. DeNavas-Walt C, Proctor B, Smith J. Income, poverty, and health insurance coverage in the United States: 2009. US Census Bureau. September 2010. 2012.

13. R GE. Eligible uninsured African Americans: 6 in 10 could receive health insurance marketplace tax credits, Medicaid, or CHIP. U S Department of Health and Human Services; 2013.

14. Fox AM, Stazyk EC, Feng W. Administrative easing: rule reduction and Medicaid enrollment. Public Adm Rev. 2020;80(1):104-17.

15. Treasury Dot. Premium tax credit (PTC). In: Service IR, editor. Washington D C2021.

16. Kennedy BR, Mathis CC, Woods AK. African Americans and their distrust of the health care system: healthcare for diverse populations. Journal of cultural diversity. 2007;14(2).

17. Watkins-Hayes C. Race, respect, and red tape: inside the black box of racially representative bureaucracies. Journal of Public Administration Research and Theory. 2011;21[suppl_2]:i233-i51.

18. Nunnally SC. Trust in Black America: race, discrimination, and politics: NYU Press; 2012.

19. Holtzblatt J, Karpman M. Who did not get the economic impact payments by mid-to-late May, and why? Washington, DC: The Urban Institute. 2020.

20. Andrulis DP, Siddiqui NJ, Purtle J, Duchon L. Patient Protection and Affordable Care Act of 2010: advancing health equity for racially and ethnically diverse populations. 2010.

21. Andrulis D, Cooper M, Siddiqui N. The Affordable Care Act and racial and ethnic health equity series. Austin, TX: Texas Health Institute. 2013.

22. Jahnke LR, Siddiqui NJ, Andrulis DP. Marketplace consumer assistance programs and promising practices for enrolling racially and ethnically diverse communities. Texas Health Institute. 2014:38.

23. Snowden, L. R., Graaf, G., Keyes, L., Kitchens, K., Wallace, N., Ryan, A. (Under Review). Medicaid expansion and African American-white coverage and healthcare disparities: a research review.

24. Hsiang, Walter R., Adam Lukasiewicz, Mark Gentry, Chang-Yeon Kim, Michael P. Leslie, Richard Pelker, Howard P. Forman, and Daniel H. Wiznia. Medicaid patients have greater difficulty scheduling health care appointments compared with private insurance patients: a meta-analysis. INQUIRY: The Journal of Health Care Organization, Provision, and Financing 56 (January 1, 2019): 0046958019838118. https://doi.org/10.1177/0046958019838118.

25. Walker D, Nowlin EL. Public validation and its impact on the initial Affordable Care Act enrollment. Health Mark Q. 2019;36(2):107-19.

26. Blumenthal, David, and James Morone. The heart of power, with a new preface: health and politics in the oval office, 2010.

27. Lerman, Amy E., and Katherine T. McCabe. Personal experience and public opinion: a theory and test of conditional policy feedback. The Journal of Politics 79, no. 2 (April 1, 2017): 624-41. https://doi.org/10.1086/689286.

28. Oberlander, Jonathan B., and Barbara Lyons. Beyond incrementalism? SCHIP and the politics of health reform. Health Affairs 28, no. Supplement 1 (January 1, 2009): w399-410. https://doi.org/ 10.1377/hlthaff.28.3.w399.

29. Braithwaite RL, Taylor SE, Treadwell HM. Health issues in the Black community: John Wiley \& Sons; 2009.

30. $\mathrm{Hu} \mathrm{Y}$, Hoover D. Simple power and sample size estimation for non-randomized longitudinal difference in differences studies. Journal of biometrics \& biostatistics. 2018;9[5]. 
31. Wright BJ, Garcia-Alexander G, Weller MA, Baicker K. Lowcost behavioral nudges increase Medicaid take-up among eligible residents of Oregon. Health Aff. 2017;36(5):838-45.

32. Buettgens M, Kenney GM, Pan C. Variation in Marketplace enrollment rates in 2015 by state and income. Robert Wood Johnson Foundation/Urban Institute, October www urban org/sites/ default/files/publication/72436/2000487-Variation-In-Marketplace-Enrollment-Rates-In-2015-By-State-And-Income pdf. 2015.

33. Gollust SE, Wilcock A, Fowler EF, Barry CL, Niederdeppe J, Baum L, et al. TV advertising volumes were associated with insurance marketplace shopping and enrollment in 2014. Health Aff. 2018;37(6):956-63.

34. Trachtman $\mathrm{S}$. When state policy makes national politics: the case of "Obamacare" marketplace implementation. J Health Polit Policy Law. 2020;45(1):111-41.

35. Shapiro TM. The hidden cost of being African American: how wealth perpetuates inequality: Oxford University Press, USA; 2004
36. Smedley BD. The lived experience of race and its health consequences. Am J Public Health. 2012;102(5):933-5.

37. Kleven HJ, Kopczuk W. Transfer program complexity and the take-up of social benefits. Am Econ J Econ Pol. 2011;3(1):54-90.

38. Norton M, Hamel L, Brodie M. Assessing Americans' familiarity with health insurance terms and concepts. The Henry J Kaiser Family Foundation. 2014;7.

39. Spencer SJ, Logel C, Davies PG. Stereotype threat. Annu Rev Psychol. 2016;67:415-37.

40. Vargas R. How health navigators legitimize the Affordable Care Act to the uninsured poor. Soc Sci Med. 2016;165:263-70.

41. Diamond R, Dickstein MJ, McQuade T, Persson P. Insurance without commitment: evidence from the ACA Marketplaces.

Publisher's Note Springer Nature remains neutral with regard to jurisdictional claims in published maps and institutional affiliations. 